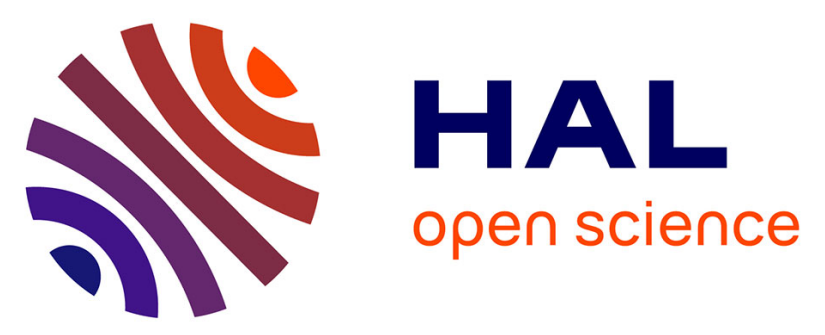

\title{
Crystalline, porous, covalent polyoxometalate-organic frameworks for lithium-ion batteries
}

Xiuqin Yu, Cuiyan Li, Yunchao Ma, Daohao Li, Hui Li, Xinyu Guan, Yushan Yan, Valentin Valtchev, Shilun Qiu, Qianrong Fang

\section{- To cite this version:}

Xiuqin Yu, Cuiyan Li, Yunchao Ma, Daohao Li, Hui Li, et al.. Crystalline, porous, covalent polyoxometalate-organic frameworks for lithium-ion batteries. Microporous and Mesoporous Materials, 2020, 299, pp.110105. 10.1016/j.micromeso.2020.110105 . hal-03035279

\section{HAL Id: hal-03035279}

\section{https://hal-normandie-univ.archives-ouvertes.fr/hal-03035279}

Submitted on 2 Dec 2020

HAL is a multi-disciplinary open access archive for the deposit and dissemination of scientific research documents, whether they are published or not. The documents may come from teaching and research institutions in France or abroad, or from public or private research centers.
L'archive ouverte pluridisciplinaire HAL, est destinée au dépôt et à la diffusion de documents scientifiques de niveau recherche, publiés ou non, émanant des établissements d'enseignement et de recherche français ou étrangers, des laboratoires publics ou privés. 
Crystalline, porous, covalent polyoxometalate-organic frameworks for

\section{lithium-ion batteries}

Xiuqin $\mathrm{Yu},{ }^{1}$ Cuiyan $\mathrm{Li}^{1},{ }^{1}$ Yunchao Ma, ${ }^{1}$ Daohao $\mathrm{Li},{ }^{1,}{ }^{*}$ Hui Li, ${ }^{1}$ Xinyu Guan, ${ }^{1}$ Yushan $\mathrm{Yan},{ }^{2}$ Valentin Valtchev, ${ }^{1,3}$ Shilun Qiu ${ }^{1} \&$ Qianrong Fang ${ }^{1, *}$

${ }^{1}$ State Key Laboratory of Inorganic Synthesis and Preparative Chemistry, Jilin University, Changchun 130012, China

${ }^{2}$ Department of Chemical and Biomolecular Engineering, Center for Catalytic Science and Technology, University of Delaware, Newark, DE 19716, USA

${ }^{3}$ Normandie Univ, ENSICAEN, UNICAEN, CNRS, Laboratoire Catalyse et Spectrochimie, 6 Marechal Juin, 14050 Caen, France

Correspondence and requests for materials should be addressed to Q.F. or D.L. (e-mail: qrfang@jlu.edu.cn or lidaohao1118@jlu.edu.cn) 
Abstract: The development of covalent organic frameworks (COFs) with new building units is of critical importance for enriching the structural diversity and expanding their functions. However, the construction of COFs has been thus far limited primarily to traditional organic linkers. Herein, we report three-dimensional porous crystalline covalent polyoxometalate-organic frameworks (CPOFs) constructed from both inorganic and organic building blocks with reversible covalent bonds. These highly crystalline CPOFs exhibited 3-fold interpenetrated diamondoid topology, permanent porosity and high stability. Furthermore, these CPOFs could be directly applied as anode materials for lithium-ion batteries (LIBs) and displayed high reversible capacity (as high as $550 \mathrm{~mA} \mathrm{~h} \mathrm{~g}{ }^{-1}$ ), rate performance, and cycling stability (up to 500 cycles).

Keywords: covalent organic frameworks; polyoxometalates; lithium-ion batteries 


\section{Introduction}

Covalent organic frameworks (COFs), constructed from elaborate integration of molecular building units into an ordered architecture through reversible covalent bonds, have attracted much attentions in recent years [1-4]. Since the seminal work of Yaghi and co-workers in 2005 [5], COF materials have shown great promise for improved performance in gas storage and separation [6-10], organic electronics [11-14], heterogeneous catalysis [15-21], and others [2230]. Although lots of two- or three-dimensional (2D or 3D) robust COFs with tunable functionality have been synthesized, the preparation of COFs is mainly limited to aromatic organic units until now. Recently, Thomas et al. reported new crystalline silicate covalent organic frameworks, based on octahedral dianionic $\mathrm{SiO}_{6}$ building units connected to organic linkers [31,32]. In theory, crystalline covalent frameworks can also be obtained by the combination of modified inorganic clusters and suitable organic building blocks, which will endow COFs with more abundant functionality and structural diversity due to the implantation of inorganic constituents. Thus, the design and synthesis of crystalline porous frameworks through covalent interaction of metal-oxo clusters and organic building units is of important but remains challenging.

In this study, we demonstrated that porous crystalline covalent polyoxometalate-organic frameworks (CPOFs), built up from both inorganic clusters and organic linkers by strong covalent bonds, can be acquired. The obtained highly crystalline 3D CPOFs feature 3-fold interpenetrated diamondoid (dia) topology, permanent porosity, and high thermal and chemical stability. In addition, owing to the presence of POM functionalized groups, CPOFs were directly used as anode materials for lithium ion batteries (LIBs), and showed high reversible capacity (> $550 \mathrm{~mA} \mathrm{~h}$ $\left.\mathrm{g}^{-1}\right)$, rate capacity, and cycling performance (> 500 cycles). 


\section{Experimental procedures}

\subsection{Synthesis of JUC-525}

A Pyrex tube (o.d. $\times$ i.d. $=10.0 \times 8.0 \mathrm{~mm}^{2}$ ) was charged with tetrakis(4-formylphenyl) methane (TFPM, $8.7 \mathrm{mg}, 0.02 \mathrm{mmol})$ and $\left[\mathrm{N}\left(\mathrm{C}_{4} \mathrm{H}_{9}\right)_{4}\right]_{3}\left[\mathrm{MnMo}_{6} \mathrm{O}_{18}\left\{\left(\mathrm{OCH}_{2}\right)_{3} \mathrm{CNH}_{2}\right\}_{2}\right]\left(\mathrm{NH}_{2}-\mathrm{POM}-\mathrm{NH}_{2}, 75.5 \mathrm{mg}\right.$, $0.04 \mathrm{mmol})$ in the mixed solution of 1,4-dioxane $(0.7 \mathrm{~mL})$ and mesitylene $(0.3 \mathrm{~mL})$ in the presence of $6 \mathrm{M}$ acetic acid catalyst $(0.15 \mathrm{~mL})$. The Pyrex tube was flash frozen in a liquid nitrogen bath, evacuated to an internal pressure of ca. $0.15 \mathrm{mmHg}$ and flame sealed, reducing the total length by ca. $10.0 \mathrm{~cm}$. Upon warming to room temperature, the reaction mixture was heated at $100{ }^{\circ} \mathrm{C}$ for 5 days to afford a pale pink precipitate which was isolated by filtration over a medium glass frit and washed with anhydrous acetonitrile $(3 \times 10.0 \mathrm{~mL})$, and THF $(3 \times 10.0 \mathrm{~mL})$. The yield is about 75\%. Anal. Calcd for $\mathrm{Mo}_{12} \mathrm{Mn}_{2} \mathrm{C}_{141} \mathrm{H}_{258} \mathrm{~N}_{10} \mathrm{O}_{48}: \mathrm{C}, 41.08 ; \mathrm{H}, 6.31 ; \mathrm{N}, 3.40 ; \mathrm{Mn}$, 2.67; Mo, 27.93. Found: $C, 41.32 ; H, 6.35 ; N, 3.44 ; M n, 2.56 ;$ Mo, 28.01 . Solid-state ${ }^{13} \mathrm{C} N M R$ (500 MHz): $\delta=152,142,134,130,120,87,73,63,57,33,24$ and 16 ppm. IR (KBr): 2963, 2870, $1637,1481,1377,1088,1025,943,914$ and $665 \mathrm{~cm}^{-1}$.

\subsection{Synthesis of JUC-526}

In a fashion similar to the preparation of JUC-525, treatment of tetrakis(4-formylphenyl) silane (TFPS, $9.0 \mathrm{mg}, 0.02 \mathrm{mmol}$ ) and $\mathrm{NH}_{2}-\mathrm{POM}-\mathrm{NH}_{2}(75.5 \mathrm{mg}, 0.04 \mathrm{mmol})$ in a solution of $0.7 \mathrm{~mL}$ 1,4dioxane : $0.3 \mathrm{~mL}$ mesitylene : $0.15 \mathrm{~mL}$ acetic acid $(6 \mathrm{M})$ at $100^{\circ} \mathrm{C}$ for 5 days afforded a pink precipitate (yield: $81 \%$ ) after purification by the above-described method. Anal. Calcd for $\mathrm{Mo}_{12} \mathrm{Mn}_{2} \mathrm{SiC}_{140} \mathrm{H}_{258} \mathrm{~N}_{10} \mathrm{O}_{48}: \mathrm{C}, 40.63 ; \mathrm{H}, 6.28 ; \mathrm{N}, 3.38 ; \mathrm{Si}, 0.68 ; \mathrm{Mn}, 2.65 ; \mathrm{Mo}, 27.82$. Found: $\mathrm{C}$, 40.82; H, 6.27; N, 3.35; Si, 0.61; Mn, 2.59; Mo, 28.03. Solid-state ${ }^{13} \mathrm{C}$ NMR (500 MHz): $\delta=155$, $145,135,129,121,88,75,50,32,22$ and 14 ppm. IR (KBr): 2963, 2870, 1640, 1481, 1088, 1025, 944,914 and $665 \mathrm{~cm}^{-1}$. 


\subsection{Electrochemical measurements}

Electrochemical measurements were performed using CR2016 coin type cells for this work. The JUC-525, JUC-526, $\mathrm{NH}_{2}-\mathrm{POM}-\mathrm{NH}_{2}$ and COF-300 were mixed with conductive carbon black (Super P) and polyvinylidene fluoride binder (PVDF) solution in a weight ratio of 6:4:1 in N-methyl-2pyrrolidinone (NMP) respectively. The slurry was casted on the $\mathrm{Cu}$ foil and dried for $10 \mathrm{~h}$ at $100{ }^{\circ} \mathrm{C}$ under vacuum to remove NMP. The 2016 type coin cells were assembled in an Ar-filled glove box. Lithium metal was used as the reference electrode and counter electrode, and the separator was a Whatman glass fiber membrane. The electrolyte composition contained $1 \mathrm{M}$ $\mathrm{LiPF}_{6}$ in a mixture of dimethyl carbonate (DMC) and ethylene carbonate (EC) $(1: 1 \mathrm{v} / \mathrm{v})$. The discharge and charge measurements were carried out on a Land instruments CT2001A testing system at various current densities of $50-2000 \mathrm{~mA} \mathrm{~g}^{-1}$ with a cut off voltage of $0.01-3.0 \mathrm{~V} \mathrm{vs}$ $\mathrm{Li}^{+} / \mathrm{Li}$. Cyclic voltammetry (CV) measurement was conducted on a $\mathrm{CHI} 760 \mathrm{E}$ electrochemical workstation using the coin cells.

\subsection{Characterization}

All starting materials and solvents, unless otherwise noted, were obtained from J\&K scientific LTD [33]. $\mathrm{NH}_{2}-\mathrm{POM}-\mathrm{NH}_{2}$, TFPM and TFPS and COF-300 was synthesized by the method of literatures. All products were isolated and handled under nitrogen using either glovebox or Schlenk line techniques. ${ }^{1} \mathrm{H}$ NMR spectra were recorded on an AV400 NMR spectrometer. ${ }^{13} \mathrm{C}$ NMR spectra were recorded on an AVIII $500 \mathrm{MHz}$ solid-state NMR spectrometer. The FT-IR spectra $(\mathrm{KBr})$ were obtained using a SHIMADZU IRAffinity-1 Fourier transform infrared spectrophotometer. Thermogravimetric analysis (TGA) was recorded on a SHIMADZU DTG-60 thermal analyzer with $\mathrm{N}_{2}$ flow rate of $30 \mathrm{~mL} \mathrm{~min}^{-1}$ at a heating rate of $10^{\circ} \mathrm{C} \mathrm{min}^{-1}$ to $600{ }^{\circ} \mathrm{C}$. PXRD data were collected on a PANalytical B.V. Empyrean powder diffractometer using a Cu Ka source 
$(\lambda=1.5418 \AA)$ over the range of $2 \theta=2.0-40.0^{\circ}$ with a step size of $0.02^{\circ}$ and $2 \mathrm{~s}$ per step. The sorption isotherm for $\mathrm{N}_{2}$ was measured by using a Quantachrome Autosorb-IQ analyzer with ultra-high-purity gas (99.999\% purity). Before gas adsorption measurements, the samples ( 50.0 $\mathrm{mg}$ ) were degassed at $85{ }^{\circ} \mathrm{C}$ under dynamic vacuum for $12 \mathrm{~h}$. To estimate the pore size distributions, nonlocal density functional theory (NLDFT) was applied to analyze the $\mathrm{N}_{2}$ isotherm on the basis of the model of $\mathrm{N}_{2} @ 77 \mathrm{~K}$ on carbon with slit pores and the method of non-negative regularization. The SEM images were obtained on JEOL JSM6700 scanning electron microscope. Element analysis was carried out on a Germany Elementary large sample volume element analyzer, vario MACRO cube CHNS.

\section{Results and discussion}

\subsection{Design of CPOFs}

Our strategy for preparation of CPOFs is based on an Anderson-type anionic POM [34], $\mathrm{NH}_{2}-$ POM-NH $\mathrm{NH}_{2}$ (Fig. 1a), which is modified with $-\mathrm{NH}_{2}$ and has tetrabutylammonium (TBA) as the counter cation. It is well known that POMs, as a large group of mostly anionic polynuclear metaloxo clusters, have been used as an outstanding functionalized inorganic building blocks for the design and construction of different structures with many attractive applications, such as POMbased metal-organic frameworks (MOFs) through coordination bonds [35,36]. Given the appropriate modification of POMs, these inorganic building units are expected to be promising functionalized building blocks for crystalline porous frameworks with high stability based on strong covalent bonds. In the model condensation reaction of $\mathrm{NH}_{2}-\mathrm{POM}-\mathrm{NH}_{2}$ with benzaldehyde, water molecules are eliminated to yield a model molecule based on $\mathrm{C}=\mathrm{N}$ bonds (Section $\mathrm{S} 1.5$, ESI). In the light of this reaction, $\mathrm{NH}_{2}-\mathrm{POM}-\mathrm{NH}_{2}$ was chosen as a 2-connected linear linker, and TFPM (Fig. 1b) or TFPS (Fig. 1c) was used as a typical 4-connected tetrahedral building unit. 
Based on the Schiff-base chemistry, the condensation of $\mathrm{NH}_{2}-\mathrm{POM}-\mathrm{NH}_{2}$ and TFPM or TFPS resulted in two novel 3D CPOFs, denoted as JUC-525 (JUC = Jilin University China, Fig. 1d) and JUC-526 (Fig. 1e). Due to the association of linear and tetrahedral building blocks, the resulting structures tend to be dia networks (Fig. 1f), e.g., 3-fold interpenetrated dia topology (Fig. 1g) [37].

\subsection{Physicochemical properties}

A set of complementary methods was used to obtain detail information of the physicochemical properties of CPOFs. Scanning electron microscopy (SEM) images showed that both materials possessed uniform morphology (Fig. 2a and 2b). Fourier transform infrared (FT-IR) spectra (Fig. 3a and 3b) showed a new peak at $1637 \mathrm{~cm}^{-1}$ for JUC-525 or $1640 \mathrm{~cm}^{-1}$ for JUC-526, which is characteristic of $\mathrm{C}=\mathrm{N}$ stretching vibration. The concomitant disappearance of the $\mathrm{C}=\mathrm{O}$ bond (1697 $\mathrm{cm}^{-1}$ for TFPM and $1703 \mathrm{~cm}^{-1}$ for TFPS) and the N-H bond $\left(3286 \mathrm{~cm}^{-1}\right.$ and $3369 \mathrm{~cm}^{-1}$ ) of $\mathrm{NH}_{2}-\mathrm{POM}-\mathrm{NH}_{2}$ demonstrated that the condensation reaction took place. The solid state ${ }^{13} \mathrm{C}$ cross-polarization magic-angle-spinning (CP/MAS) NMR spectra further confirmed the presence of carbons from the $\mathrm{C}=\mathrm{N}$ bond at $152 \mathrm{ppm}$ for JUC-525 and $155 \mathrm{ppm}$ for JUC-526 as well as from guest molecules (Fig. $3 c$ and 3 d). These results are consistent with those from the model molecule (Figs. S1 and S2, ESI). According to the thermogravimetric analysis (TGA), these CPOFs can be stable up to $300{ }^{\circ} \mathrm{C}$ (Figs. S3 and S4, ESI). In addition, both CPOFs had high chemical stability and could be conserved in various organic solvents and acid/base aqueous solutions with $\mathrm{pH}$ ranging between 1 and 12 (Figs. S5-8, ESI).

\subsection{Crystalline structural resolution}

The experimental power X-ray diffraction (PXRD) patterns of CPOFs exhibited intense diffraction peaks, indicating the highly crystalline nature of the solids (Fig. $2 \mathrm{c}$ and $2 \mathrm{~d}$ ). No additional peaks 
revealing the presence of initial or other crystalline materials were observed (Figs. S9 and S10, ESI). After a geometrical energy minimization by using Materials Studio software package [38] based on the 3-fold interpenetrated dia topology, the unit cell parameters were obtained ( $a=b$ $=38.1716 \AA, c=13.6483 \AA$ and $\alpha=\beta=\gamma=90^{\circ}$ for JUC-525; $a=b=39.0541 \AA, c=13.7657 \AA$ and $\alpha=\beta=\gamma=90^{\circ}$ for JUC-526). The full profile pattern matching (Pawley) refinements were performed from the experimental data. Strong PXRD peaks at 6.54, 6.89, 8.29, 9.23, 10.38 and $11.54^{\circ}$ for JUC-525 correspond to the (220), (101), (211), (400), (420) and (430) Bragg peaks of space group $P 4_{3} 2_{1} 2$ (No. 96); peaks at $6.40,6.82,8.19,9.06,10.34$ and $11.33^{\circ}$ for JUC-526 belong to the (220), (101), (211), (400), (420) and (430) Bragg peaks of the same space group with JUC-525. The refinement yielded PXRD profiles nearly equivalent to the experiment patterns with good agreement factors $(R \mathrm{wp}=4.65 \%$ and $R p=3.57 \%$ for JUC-525; $R \mathrm{wp}=2.77 \%$ and $R p=2.18 \%$ for JUC-526). Besides the 3 -fold interpenetrated dia network, PXRD patterns were also calculated on the basis of non-, 2-fold or 4-fold interpenetrated dia network for both CPOFs. However, their simulated PXRD patterns could not match to the experimental ones (Figs. S11-20, ESI). According to the above results, both 3D CPOFs were proposed to be 3 -fold interpenetrated dia networks and had microporous cavities of about $12.0 \AA$, which was occupied by TBA cations (Fig. 4 and Figs. S21-23, ESI).

\subsection{Gas adsorption}

The permanent porosity and specific surface areas of CPOFs were examined by nitrogen $\left(\mathrm{N}_{2}\right)$ adsorption-desorption analysis at $77 \mathrm{~K}$ (Fig. 5a and 5b). Both CPOFs exhibited the typical characteristic of crystalline microporous materials with a sharp uptake below $0.05 \mathrm{P} / \mathrm{P}_{0}$. The slight desorption hysteresis and inclination of isotherms after $0.90 \mathrm{P} / \mathrm{P}_{0}$ can be attributed to textural mesopores resulting from the agglomeration of crystals [39]. The Brunauer-Emmett- 
Teller (BET) surface area was $372.9 \mathrm{~m}^{2} \mathrm{~g}^{-1}$ and $386.9 \mathrm{~m}^{2} \mathrm{~g}^{-1}$ for JUC-525 and JUC-526, respectively (Figs. S24 and S25, ESI). By using the model of nonlocal density functional theory (NLDFT), the pore size distributions were evaluated to be $6.2 \AA$ for JUC-525 and $6.6 \AA$ for JUC-526 (Figs. S26 and S27, ESI). These values are lower than those predicted from their crystal structures due to the presence of TBA cations in the pores. Furthermore, the adsorption isotherms of $\mathrm{CO}_{2}, \mathrm{~N}_{2}$ and $\mathrm{CH}_{4}$ for CPOFs were also measured at $273 \mathrm{~K}$ (Fig. $5 \mathrm{c}$ and $5 \mathrm{~d}$ ). Both CPOFs exhibited high $\mathrm{CO}_{2}$ uptakes, $76.2 \mathrm{mg} \mathrm{g}^{-1}$ for JUC-525 and $66.0 \mathrm{mg} \mathrm{g}^{-1}$ for JUC-526 respectively, which are much higher than other gases, such as $\mathrm{CH}_{4}\left(5.0 \mathrm{mg} \mathrm{g}^{-1}\right.$ for JUC-525 and $4.7 \mathrm{mg} \mathrm{g}^{-1}$ for JUC-526) and $\mathrm{N}_{2}(2.9 \mathrm{mg}$ $\mathrm{g}^{-1}$ for JUC-525 and $3.1 \mathrm{mg} \mathrm{g}^{-1}$ for JUC-526). The ideal adsorption selectivity of CPOFs was calculated from the ratio of the initial slopes in the Henry region of the isotherms (Figs. S28 and S29, ESI) [40], and a high selectivity of $\mathrm{CO}_{2} / \mathrm{N}_{2}$ and $\mathrm{CO}_{2} / \mathrm{CH}_{4}$ was observed as 27.3 and 15.5 for JUC-525 as well as 33.8 and 20.3 for JUC-526. It is well known that quaternary ammonium ions have good affinity to $\mathrm{CO}_{2}[41]$; therefore, the high selectivity of CPOFs to $\mathrm{CO}_{2}$ can be attributed to TBA cations in their pores.

\subsection{Electrochemical properties}

Given the high crystallinity, stability and permanent porosity of CPOFs, we investigated the energy storage property of JUC-526 as anode materials for LIBs. LIBs as one of the most promising power sources can be applied for electric vehicles thanks to their light weight, high energy density and environmental friendliness $[42,43]$. The cyclic voltammetry (CV) of JUC-526 gave rise to an irreversible reductive peak at approximately $0.68 \mathrm{~V}$ in the first reductive cycle (Fig. 6a). This can be associated with the formation of a solid electrolyte interphase (SEI) film. Subsequently, the reversibility of reductive peak at $0.75 \mathrm{~V}$ and oxidative peak at $1.36 \mathrm{~V}$ was observed, which suggests that $\mathrm{Li}^{+}$insertion/extraction is reversible. These results are consistent 
with the galvanostatic charge-discharge profiles (Fig. 6b). The first discharge and charge capacities of JUC-526 were 750.6 and $509.6 \mathrm{~mA} \mathrm{~h} \mathrm{~g}{ }^{-1}$ respectively, giving an initial coulombic efficiency (CE) of $67.9 \%$, which can be ascribed to the production of SEI film and the decomposition of electrolyte [44]. Furthermore, the cycling stability of JUC-526 was studied at a current density of $100 \mathrm{~mA} \mathrm{~g}^{-1}$ (Fig. 6c). After 500 cycles, the discharge/charge capacities of JUC526 anode still maintained a high value of 550.6/548.6 $\mathrm{mA} \mathrm{h} \mathrm{g}^{-1}$ with the coulombic efficiency of 99.6\%, which demonstrates a higher stability than those from most POM-based MOFs (only 100 cycles) $[45,46]$. The rate performance has also been evaluated at various current densities in the range of 0.05 to $2.0 \mathrm{~A} \mathrm{~g}^{-1}$ (Fig. 6d). Notably, even at the current density of $0.2 \mathrm{~A} \mathrm{~g}^{-1}$, JUC-526 showed a reversible capacity as high as $441.2 \mathrm{~mA} \mathrm{~h} \mathrm{~g}^{-1}$, which is higher than that of graphite as the commercial anode material with a theoretical capacity of $372 \mathrm{~mA} \mathrm{~h} \mathrm{~g}{ }^{-1}$ [47]. When the current density was restored to $0.1 \mathrm{~A} \mathrm{~g}^{-1}$, the capacity of JUC-526 exhibited the reversible capacity of $503.3 \mathrm{~mA} \mathrm{~h} \mathrm{~g}{ }^{-1}$, indicating an excellent cycling performance. The electrochemical properties of JUC-525 are similar with those of JUC-526 (Figs. S30-33, ESI). For the sake of comparison, we also tested the battery performance of pure $\mathrm{NH}_{2}-\mathrm{POM}-\mathrm{NH}_{2}$ and COF-300 [48] as a typical unfunctionalized 3D COF. In contrast, they showed much lower discharge capacities and poor cycling performance (Figs. S34 and S35, ESI). These results indicated that the assembly of POMs into covalent organic frameworks architectures by strong covalent bond could significantly enhance the performance of LIBs owing to their high surface areas and structural stability.

\section{Conclusions}

In conclusion, we have synthesized two 3D porous crystalline CPOFs formed from hybrid inorganic clusters and organic building blocks via covalent bonds. Both CPOFs showed high crystallinity, permanent porosity, and good thermal and chemical stability. Furthermore, when 
applied as an anode material for LIBs, JUC-526 displayed excellent reversible capacity of $550 \mathrm{~mA}$ $\mathrm{h} \mathrm{g}^{-1}$ at a current density of $100 \mathrm{~mA} \mathrm{~h} \mathrm{~g}{ }^{-1}$, rate capacity, and cycling performance (> 500 cycles). CPOFs successfully prepared in this work may not only open a new strategy to create 3D functionalized crystalline porous frameworks but also push forward the electrochemical applications of crystalline porous frameworks.

\section{Acknowledgements}

This work was supported by National Natural Science Foundation of China (21571079, 21621001, 21390394, 21571076, and 21571078), "111" project (B07016 and B17020), and the program for JLU Science and Technology Innovative Research Team. Q.F. and V.V. acknowledge the Thousand Talents program (China). V.V., S.Q. and Q.F. acknowledge funding from the FrenchSino International Laboratory (LIA) "Zeolites".

\section{References}

[1] C. S. Diercks, O. M. Yaghi, Science 355 (2017) 923.

[2] N. Huang, P. Wang, D. L. Jiang, Nat. Rev. Mater. 1 (2016) 16068.

[3] S. Y. Ding, W. Wang, Chem. Soc. Rev. 42 (2013) 548.

[4] J. W. Colson, W. R. Dichtel, Nat. Chem. 5 (2013) 453.

[5] A. P. Côté, A. I. Benin, N. W. Ockwig, M. O'Keeffe, A. J. Matzger, O. M. Yaghi, Science 310 (2005) 1166.

[6] H. M. El-Kaderi, J. R. Hunt, J. L. Mendoza-Cortes, A. P. Côté, R. E. Taylor, M. O'Keeffe, O. M. Yaghi, Science 316 (2007) 268. 
[7] S. S. Han, H. Furukawa, O. M. Yaghi, W. A. Goddard III, J. Am. Chem. Soc. 130 (2008) 11580.

[8] P. Kuhn, M. Antonietti, A. Thomas, Angew. Chem. Int. Ed. 47 (2008) 3450.

[9] S. Wang, Q. Wang, P. Shao, Y. Han, X. Gao, L. Ma, S. Yuan, X. Ma, J. Zhou, X. Feng, B. Wang, J. Am. Chem. Soc. 139 (2017) 4258.

[10] X. Y. Guan, Y. C. Ma, H. Li, Y. Yusran, M. Xue, Q. R. Fang, Y. S. Yan, V. Valtchev, S. L. Qiu, J. Am. Chem. Soc. 140 (2018) 4494.

[11] S. Wan, J. Guo, J. Kim, H. Ihee, D. Jiang, Angew. Chem. Int. Ed. 47 (2008) 8958.

[12] M. Dogru, M. Handloser, F. Auras, T. Kunz, D. Medina, A. Hartschuh, P. Knochel, T. Bein, Angew. Chem. Int. Ed. 52 (2013) 2920.

[13] G. H. V. Bertrand, V. K. Michaelis, T. C. Ong, R. G. Griffin, M. Dincă, Proc. Natl. Acad. Sci. USA 110 (2013) 4923.

[14] H. Li, J. H. Chang, S. S. Li, X. Y. Guan, D. H. Li, C. Y. Li, L. X. Tang, M. Xue, Y. S. Yan, V. Valtchev, S. L. Qiu, Q. R. Fang, J. Am. Chem. Soc. 141 (2019) 13324.

[15] S. Y. Ding, J. Gao, Q. Wang, Y. Zhang, W. G. Song, C. Y. Su, W. Wang, J. Am. Chem. Soc. 133 (2011) 19816.

[16] Q. R. Fang, S. Gu, J. Zheng, Z. B. Zhuang, S. L. Qiu, Y. S. Yan, Angew. Chem. Int. Ed. 53 (2014) 2878.

[17] V. S. Vyas, F. Haase, L. Stegbauer, G. Savasci, F. Podjaski, C. Ochsenfeld, B. V. Lotsch, Nat. Commun. 6 (2015) 8508. 
[18] H. Li, Q. Y. Pan, Y. C. Ma, X. Y. Guan, M. Xue, Q. R. Fang, Y. S. Yan, V. Valtchev, S. L. Qiu, J. Am. Chem. Soc. 138 (2016) 14783.

[19] Q. Sun, B. Aguila, J. Perman, N. Nguyen, S. Q. Ma, J. Am. Chem. Soc. 138 (2016) 15790.

[20] X. Wang, X. Han, J. Zhang, X. Wu, Y. Liu, Y. Cui, J. Am. Chem. Soc. 138 (2016) 12332.

[21] S. C. Yan, X. Y. Guan, H. Li, D. H. Li, M. Xue, Y. S. Yan, V. Valtche v, S. L. Qiu, Q. R. Fang, J. Am. Chem. Soc. 141 (2019) 2920.

[22] S. Chandra, T. Kundu, S. Kandambeth, R. BabaRao, M. Y. Arathe, S. M. Kunjir, R. Banerjee, J. Am. Chem. Soc. 136 (2014) 6570.

[23] Q. R. Fang, Z. B. Zhuang, S. Gu, R. B. Kaspar, J. Zheng, J. H. Wang, S. L Qiu, Y. S. Yan, Nat. Commun. 5 (2014) 4503.

[24] T. Y. Zhou, S. Q. Xu, Q. Wen, Z. F. Pang, X. Zhao, J. Am. Chem. Soc. 136 (2014) 15885.

[25] Y. Du, H. Yang, J. M. Whiteley, S. Wan, Y. Jin, S. H. Lee, W. Zhang, Angew. Chem. Int. Ed. 55 (2016) 1737.

[26] E. Q. Jin, M. Asada, Q. Xu, S. Dalapati, M. A. Addicoat, M. A. Brady, H. Xu, T. Nakamura, T. Heine, Q. H. Chen, D. L. Jiang, Science 357 (2017) 673.

[27] Z. L. Li, H. Li, X. Y. Guan, J. J. Tang, Y. Yusran, Z. Li, M. Xue, Q. R. Fang, Y. S. Yan, V. Valtchev, S. L. Qiu, J. Am. Chem. Soc. 139 (2017) 17771.

[28] Y. Y. Zhang, J. Y. Duan, D. Ma, P. F. Li, S. W. Li, H. W. Li, J. W. Zhou, X. J. Ma, X. Feng, B. Wang, Angew. Chem. Int. Ed. 56 (2017) 16313. 
[29] Q. Y. Lu, Y. C. Ma, H. Li, X. Y. Guan, Y. Yusran, M. Xue, Q. R. Fang, Y. S Yan, S. L. Qiu, V. Valtchev, Angew. Chem. Int. Ed. 57 (2018) 6042.

[30] X. Y. Guan, H. Li, Y. C. Ma, M. Xue, Q. R. Fang, Y. S. Yan, V. Valtchev, S. L. Qiu, Nat. Chem. 11 (2019) 587.

[31] J. Roeser, D. Prill, M. J. Bojdys, P. Fayon, A. Trewin, A. N. Fitch, M. U. Schmidt, A. Thomas, Nat. Chem. 9 (2017) 977.

[32] O. Yahiaoui, A. N. Fitch, F. Hoffmann, M. Fröba, A. Thomas, J. Roeser, J. Am. Chem. Soc. 140 (2018) 5330.

[33] https://www.jkchemical.com/.

[34] P. R. Marcoux, B. Hasenknopf, J. Vaissermann, P. Gouzerh, Eur. J. Inorg. Chem. 13 (2003) 2406.

[35] D. Y. Du, J. S. Qin, S. L. Li, Z. M. Su, Y. Q. Lan, Chem. Soc. Rev. 43 (2014) 4615.

[36] D. L. Long, E. Burkholder, L. Cronin, Chem. Soc. Rev. 36 (2007) 105.

[37] C. Bonneau, O. Delgado-Friedrichs, M. O'Keeffe, O. M. Yaghi, Acta Crystallogr. A60 (2004) 517.

[38] Materials Studio ver. 7.0; Accelrys Inc.; San Diego, CA.

[39] Q. R. Fang, J. H. Wang, S. Gu, R. B. Kaspar, Z. B. Zhuang, J. Zheng, H. X. Guo, S. L. Qiu, Y. S. Yan, J. Am. Chem. Soc. 137 (2015) 8352.

[40] W. Henry, Philos. Trans. R. Soc. Lond. 93 (1803) 29.

[41] C. C. Guo, Clean Coal Technology. 23 (2017) 114. 
[42] P. Poizot, S. Laruelle, S. Grugeon, L. Dupont, J. M. Tarascon, Nature 407 (2000) 496.

[43] J. Vetter, P. Novák, M. R. Wagner, C. Veit, K-C. Möller, J. O. Besenhard, M. Winter, M. Wohlfahrt-Mehrens, C. Vogler, A. Hammouche, J. Power Sources. 147 (2005) 269.

[44] E. Buiel, J. R. Dahn, J. Electrochem. Soc. 145 (1998) 1977.

[45] X. Y. Yang, T. Wei, J. S. Li, N. Sheng, P. P. Zhu, J. Q. Sha, T. Wang, Y. Q. Lan, Inorg. Chem. 56 (2017) 8311.

[46] M. T. Li, X. Y. Yang, J. S. Li, N. Sheng, G. D. Liu, J. Q. Sha, Y. Q. Lan, Inorg. Chem. 57 (2018) 3865.

[47] J. M. Tarascon, M. Armand, Nature 414 (2001) 359.

[48] F. J. Uribe-Romo, J. R. Hunt, H. Furukawa, C. Klöck, M. O’Keeffe, O. M. Yaghi, J. Am. Chem. Soc. 131 (2009) 4570. 
(a)

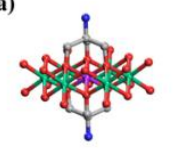

III

III<smiles>C=C</smiles>

$\mathrm{NH}_{2}-\mathrm{POM}-\mathrm{NH}_{2}$ (b)

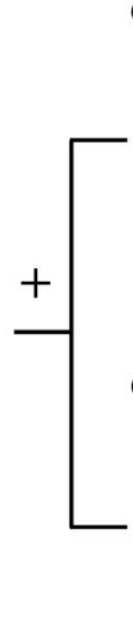

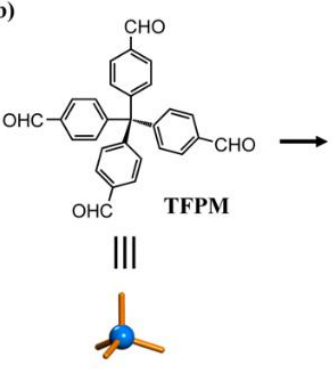

III

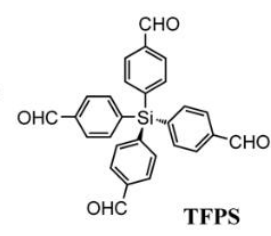

(d)

d)

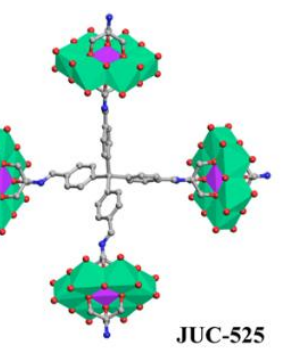

(e)

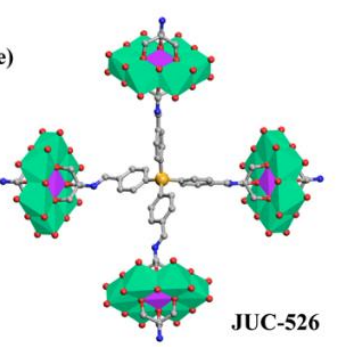

(f)

(g)
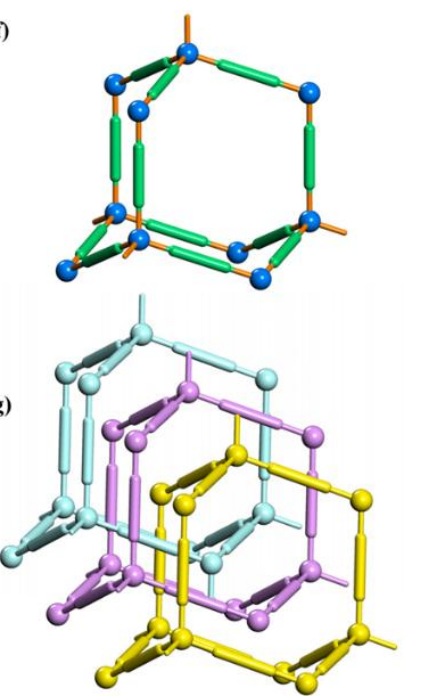

Fig. 1. Strategy for preparing CPOFs. Condensation of an Anderson-type anionic polyoxometalate (POM) modified with $-\mathrm{NH}_{2}\left(\mathrm{NH}_{2}-\mathrm{POM}-\mathrm{NH}_{2}\right.$, a) and typical 4-connected tetrahedral building units, tetrakis(4-formylphenyl) methane (TFPM, b) or tetrakis(4formyphenyl) silicane (TFPS, c) to give two novel 3D CPOFs, JUC-525 (d) and JUC-526 (e). (f) Single network in dia topology. (g) 3-fold interpenetrated network in dia topology. 
(a)

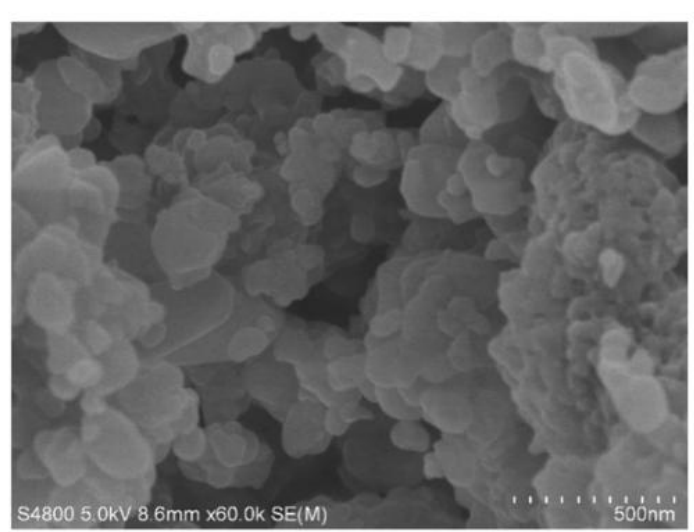

(c)

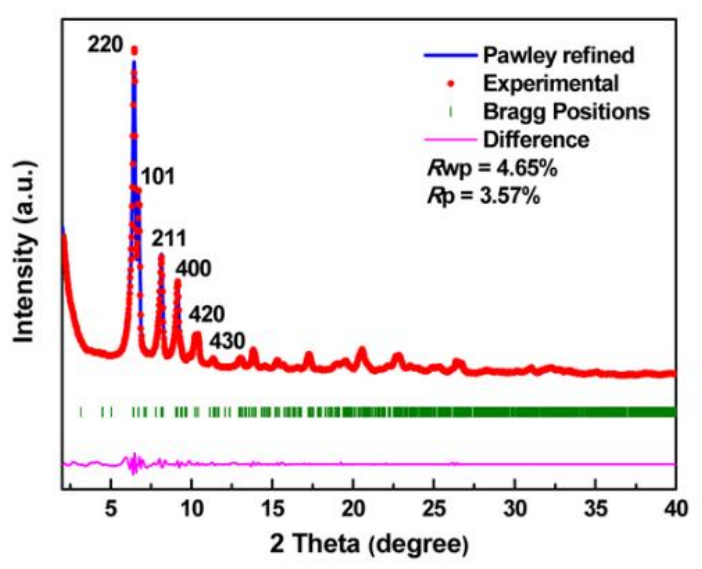

(b)

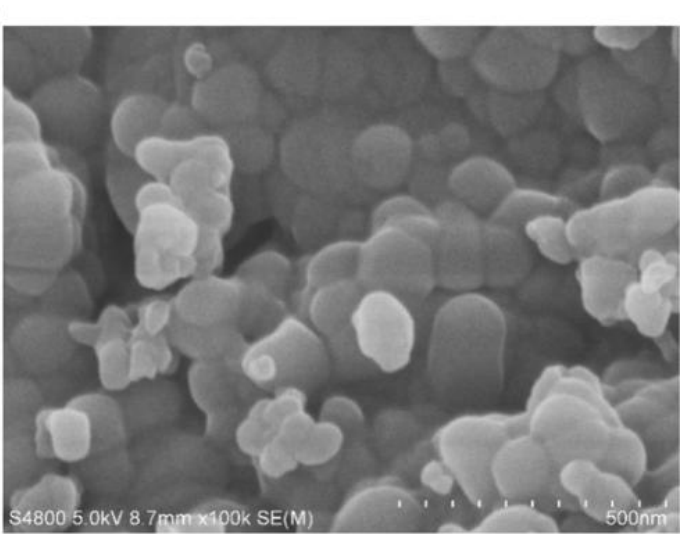

(d)

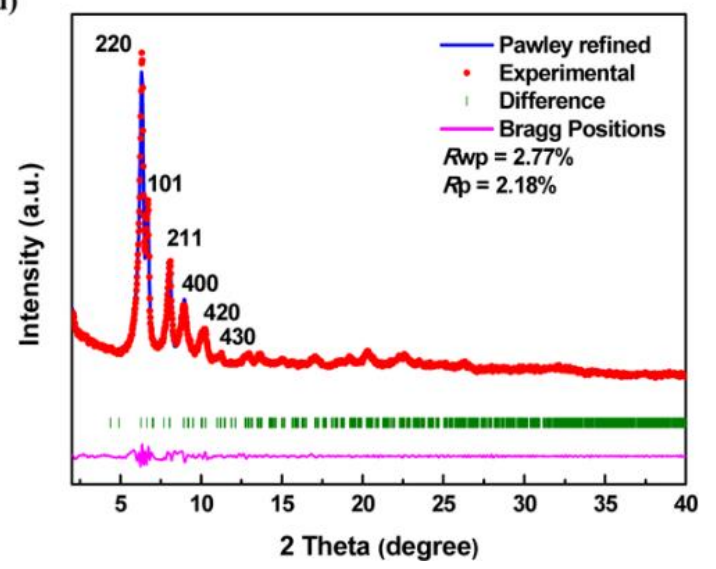

Fig. 2. The characterization of morphologies and structures of CPOFs. (a and b) SEM images of JUC-525 (a) and JUC-526 (b). (c and d) PXRD patterns of JUC-525 (c) and JUC-526 (d). 

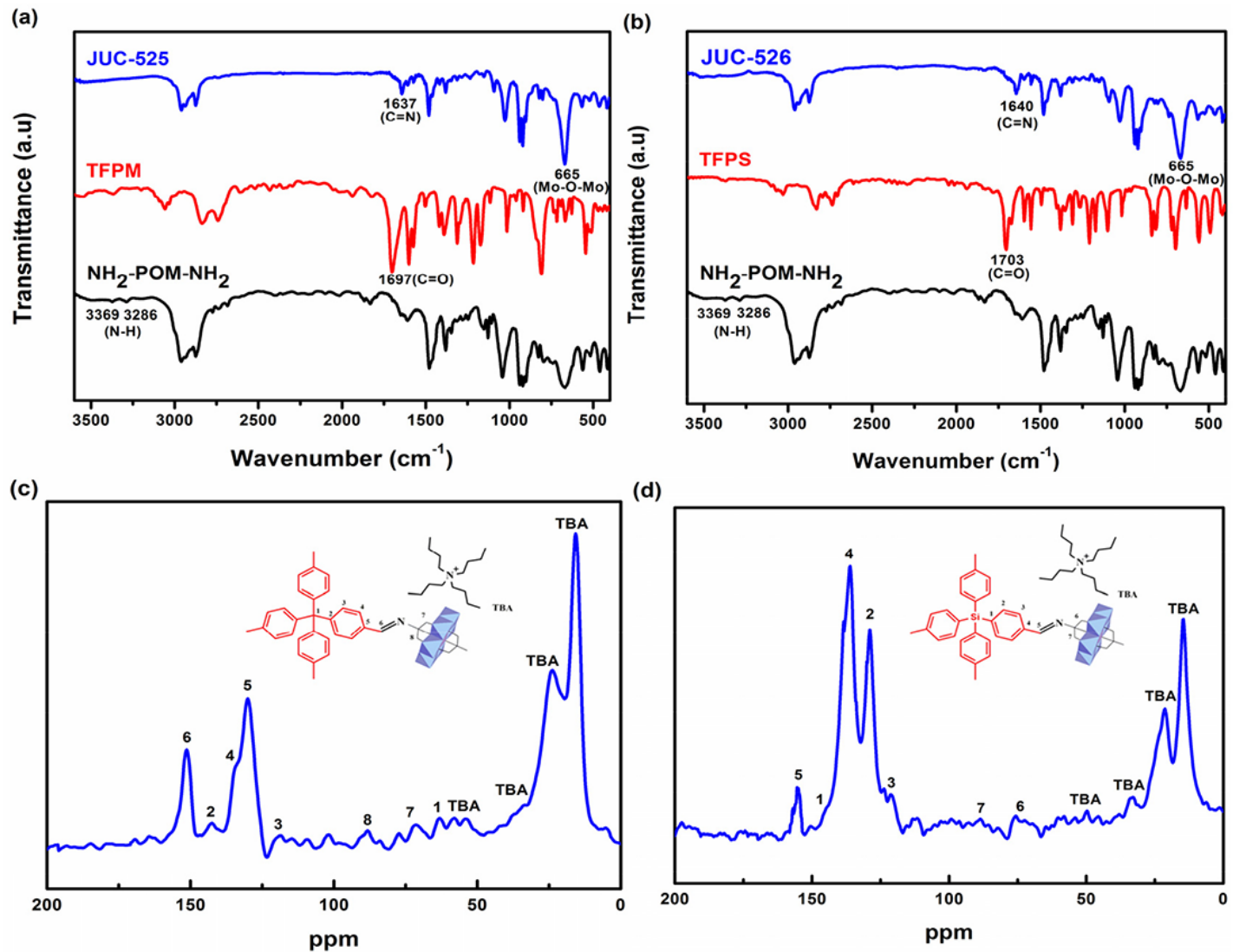

Fig. 3. The FT-IR and Solid-state ${ }^{13} \mathrm{C}$ NMR spectra of CPOFs. (a) FT- IR spectra of JUC-525 (blue), TFPM (red), and $\mathrm{NH}_{2}-\mathrm{POM}-\mathrm{NH}_{2}$ (black). (b) FT-IR spectra of JUC-526 (blue), TFPS (red), and $\mathrm{NH}_{2}-$ POM-NH ${ }_{2}$ (black). (c) Solid-state ${ }^{13} \mathrm{C}$ NMR spectrum of JUC-525. (d) Solid-state ${ }^{13} \mathrm{C}$ NMR spectrum of JUC-526. 
(a)

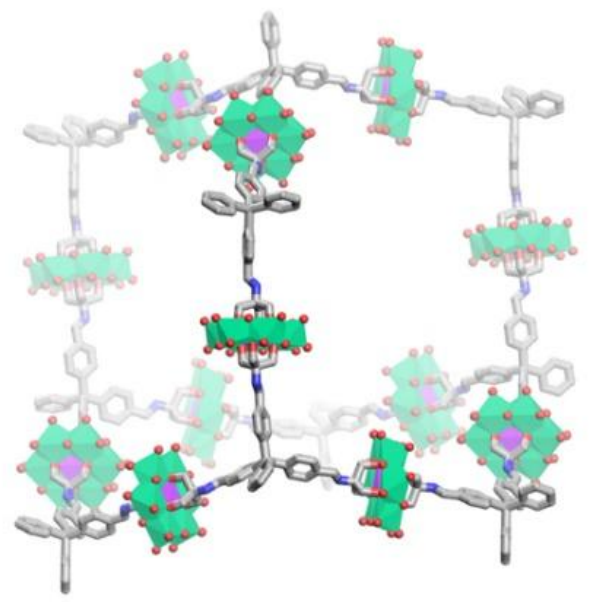

(c)

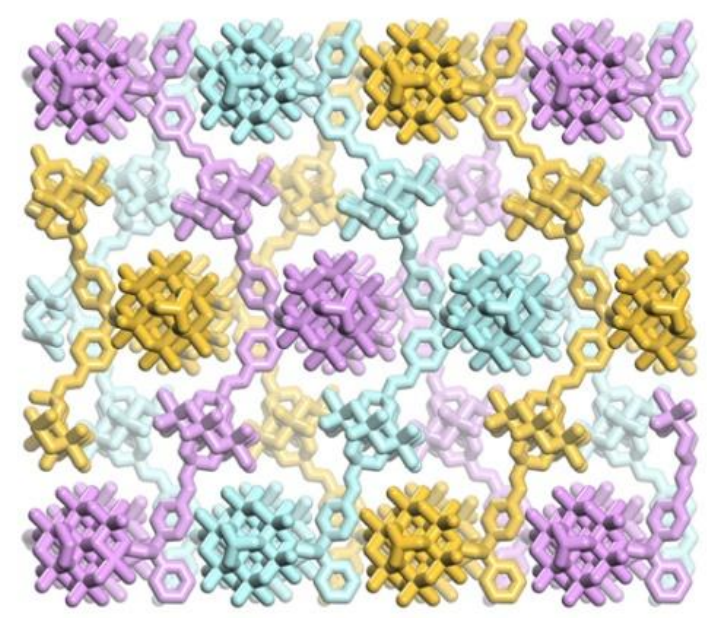

(b)

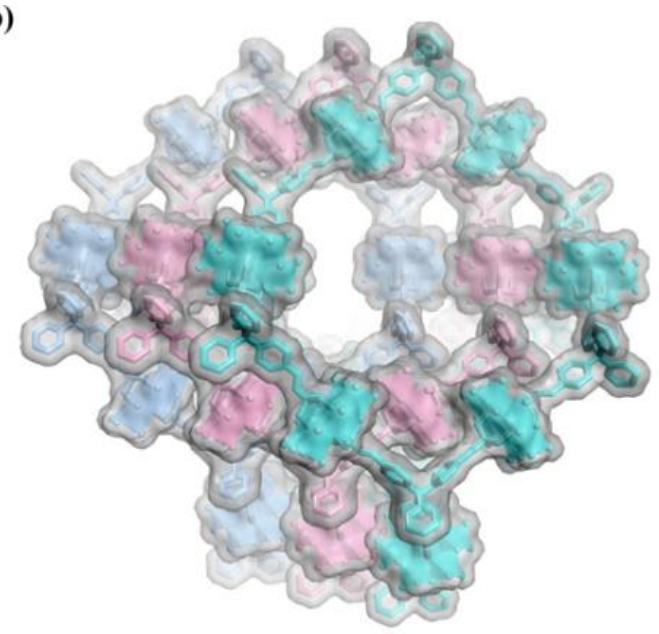

(d)

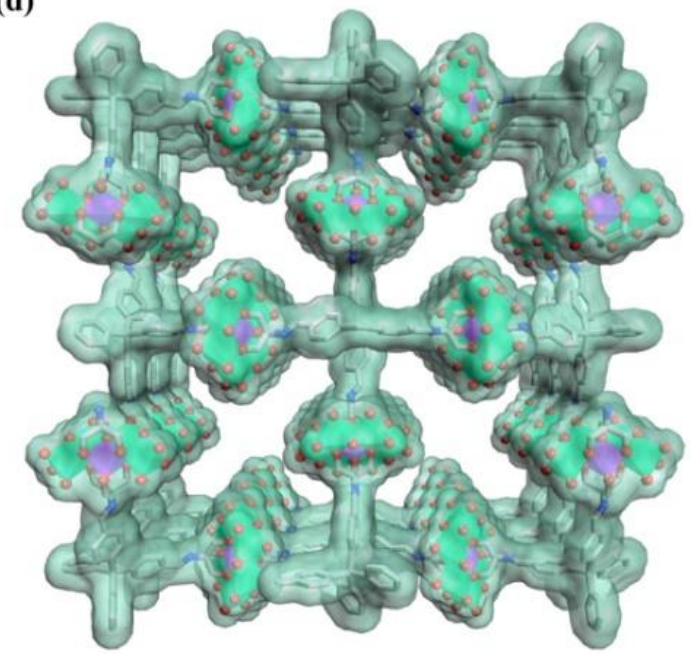

Fig. 4. Structural representations of JUC-525. (a) Single dia network. (b) 3-fold interpenetrated dia network. (c) Extended structure view along the [100] direction. (d) Microporous channels view along the [001] direction. $\mathrm{C}$, gray; $\mathrm{O}$, red; N, blue; Mn, purple; Mo, green. The hydrogen atoms and guest molecules are not shown for clarity. 

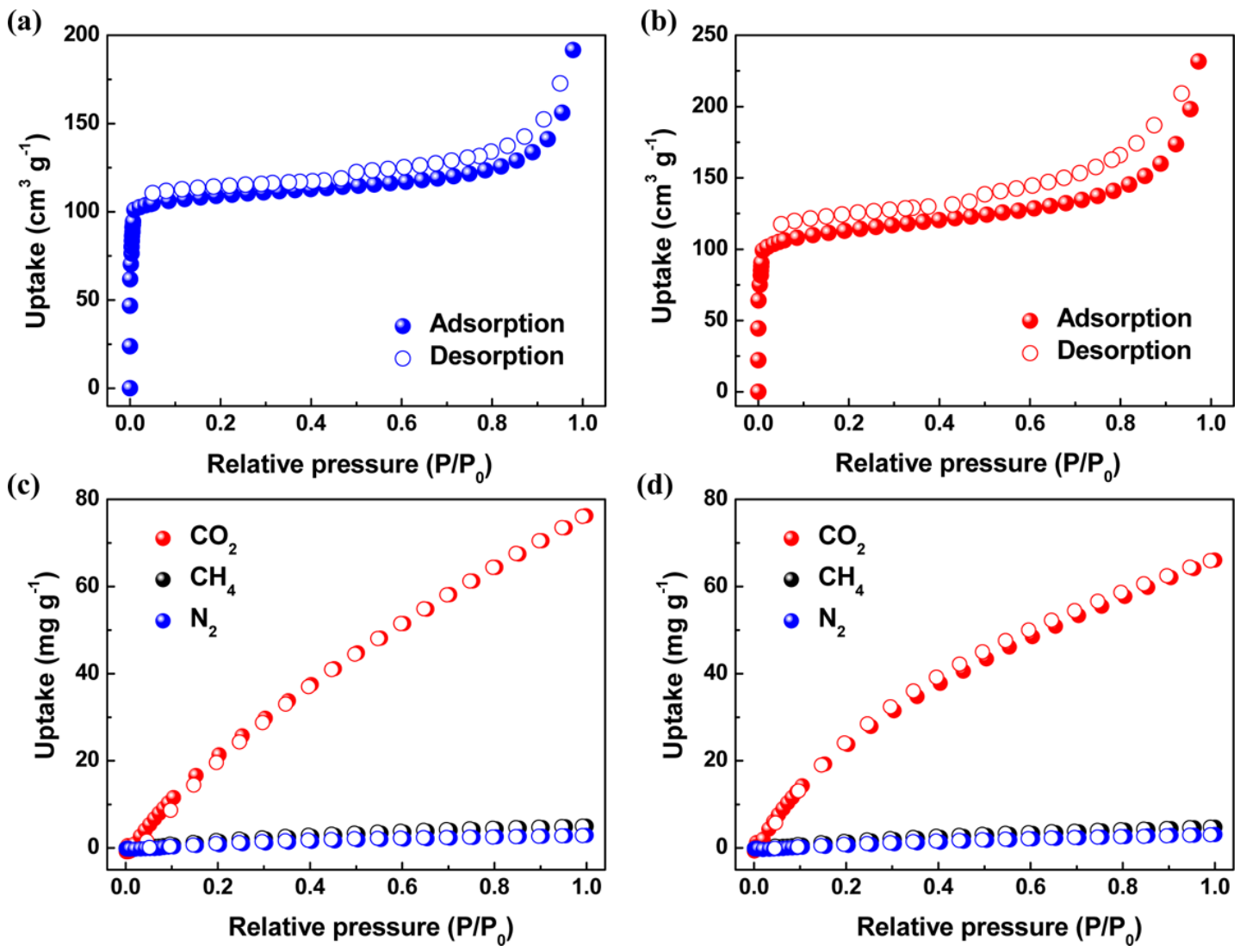

Fig. 5. Gas adsorption and desorption isotherms for CPOFs. (a and b) $\mathrm{N}_{2}$ adsorption-desorption analysis for JUC-525 (a) and JUC-526 (b) at $77 \mathrm{~K}$. (c and d) $\mathrm{CO}_{2}, \mathrm{CH}_{4}$ and $\mathrm{N}_{2}$ adsorption-desorption analysis for JUC-525 (c) and JUC-526 (d) at $273 \mathrm{~K}$. 

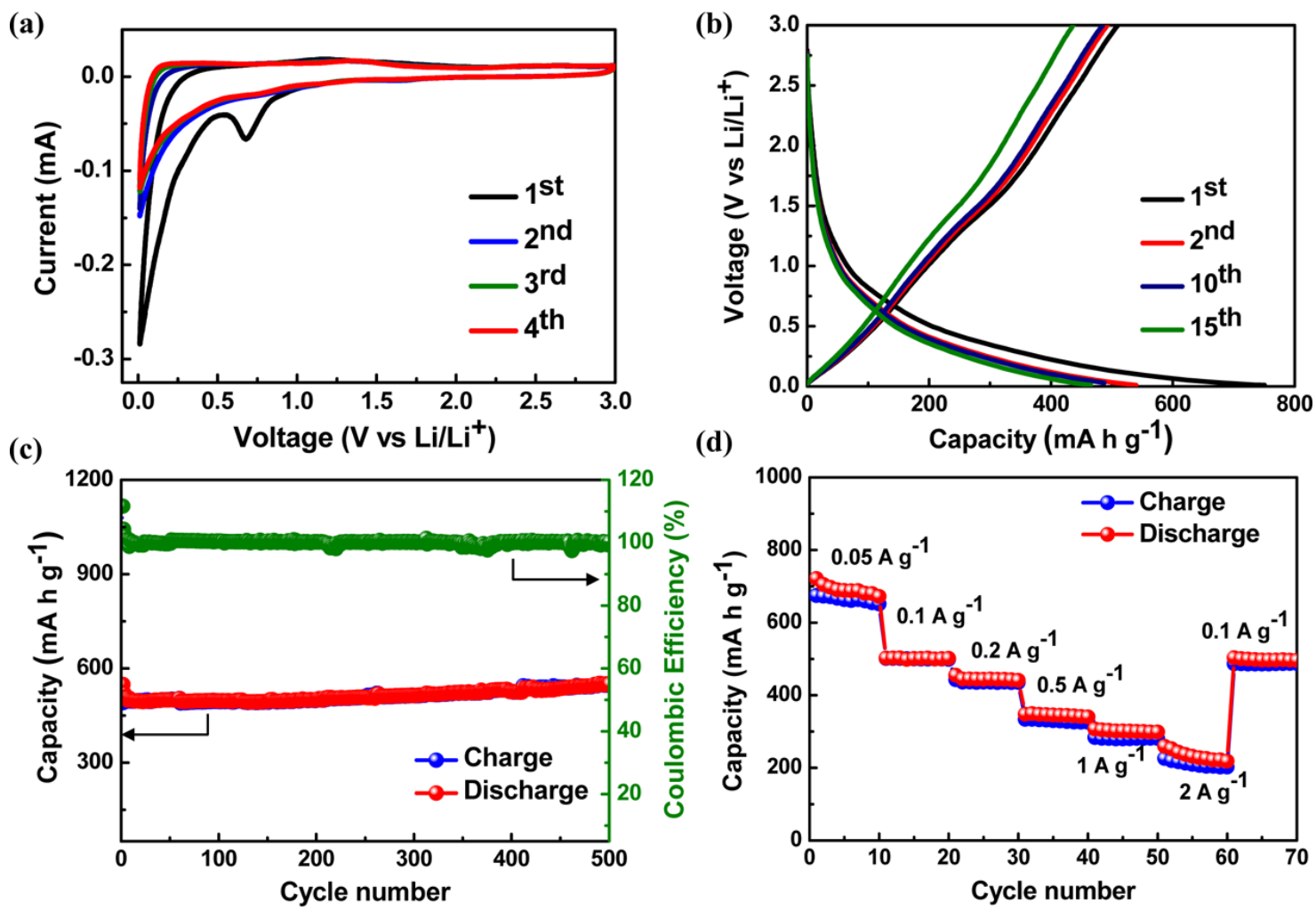

Fig. 6. Electrochemical performance of JUC-526 as anode materials for LIBs. (a) CV curves at a scan of $0.1 \mathrm{mv} \mathrm{s}^{-1}$ over the range of $0.01-3.0 \mathrm{~V}$ vs $\mathrm{Li}^{-\mathrm{Li}^{+}}$. (b) The galvanostatic charge-discharge profiles for selected cycles. (c) The cycling stability and coulombic efficiency at a current density of $100 \mathrm{~mA} \mathrm{~g}^{-1}$. (d) The rate performance at various current densities from 0.05 to $2 \mathrm{~A} \mathrm{~g}^{-1}$. 